Received Date: January 2021

Revised: March 2021

Accepted: June 2021

\title{
Determinant of Age at First Birth in Nepal: A Study of Adolescent and Youth Women in NDHS 2016
}

\author{
Prabha Khanal (M. Phil.)*
}

\begin{abstract}
First birth is one of the most significant events in woman's life which signifies her taking on the roles and responsibilities of a mother. This article tries to figure out the factors that determine the age at first birth of women aged 15 to 24 years. Utilizing the Nepal Demographic and Health Survey 2016 data, this study examines the socio economic and demographic determinants of age at first birth among the women aged 15-24 years with the 4,849 married women. The analysis has made using the mean distribution and two tailed Pearson's correlation has been used for statistical test. The result shows that women's education, occupation, wealth index and age at marriage has positive correlation with the age at first birth. It is expected that higher the use of contraceptive method has lower the fertility. Though, use of contraceptive methods seems no any association with the age of women at first birth. Study reveals that unmet need for family planning is high of that age group. That's why, supply of family planning methods of target population group can play vital role to postpone age at first birth.
\end{abstract}

Key words: Adolescent, age at first birth, marriage, youth \& determinant factor.

\section{Introduction}

Having the first birth is one of the most significant events in a woman's life, it indicates the beginning of intensive responsibilities of motherhood and childcare. It is a transition marks to a woman into motherhood. Age at first birth plays a significant role in the future life of each individual woman and has a direct relationship with fertility (Rabbi et al., 2013). The age at first birth has a bearing to the total number of births that the woman might have in her life, which impacts the size, composition, and future growth of the population (Mosammat et al., 2013). Besides that, early initiation of first birth reduces

${ }^{\star}$ Ms. Khanal is a Lecturer at the Department of Population Studies, Patan Multiple Campus, TU, Lalitpur, Nepal.Email: Sanuprabha@gmail.com 
the quality of life due to responsibilities of motherhood and childcare. Early entry into motherhood lengthens the reproductive period and subsequently increases fertility and that may adversely affect the health of mother and infant as well economic welfare of the family (Rabbi et al., 2013). Complications during pregnancy and childbirth are the leading causes of deaths for 15-19 year old girls globally where 2 percent of adolescents die at the time of pregnancy or child bearing. It can be said that the maternal mortality ratio of women aged under 20 years of age is reported 2 percent. WHO (2019) reported that the risk of maternal mortality is highest for adolescent girls under 15 years old and complications in pregnancy and childbirth are higher among adolescent girls age 10-19 compared to women 20 to 24 years of age.

Marriage is mostly defined as the onset of the socially acceptable time for sexual activity or union and childbearing by many societies in Asian and African countries. Almost all births occurs with marital union therefore, timing of first birth can be considered to be directly related with the age at union and age at cohabitation. Regmi (1995) says that women's age at first union has a sizable influence to the timing of first birth. Marriage is the most predominant context for childbearing but also one of the most important determinants of fertility. It is indicated that women who marry early will have on average a longer period of exposure to getting pregnant often leading to higher fertility (Bongarts, 1983). Particularly in South Asia where it is most prevalent, early marriage unleashes a lifetime of trauma such as school dropout rates, unwanted pregnancies, childbirth injuries and other maladies (Bangali, 2015).

Nepal holds the $17^{\text {th }}$ highest prevalence rate of child marriage in the world and the $17^{\text {th }}$ highest absolute number of child brides (UNICEF, 2018). The report of Nepal Demographic and Health Survey 2016 revealed that around 40 percent of Nepalese girls are married before their 18th birthday and 7 percent are married before the age of 15 . Similarly, evidence of early marriage is that the median age at first marriage is 17.9 years and 21.7 years among women and men. According to this data, women in Nepal marry about 4 years earlier than men. Report noted that among the women aged from 25-49, 13 percent are married at age of 15 while only 3 percent of men married at that age. There are significant difference between men and women of early marriage. While 52 percent of women has been married by age of 18 as compared to 19 percent of men (MoHP, 2017).

The UNICEF (2018) report revealed that a large number of women become mother before they reached age 20 . Nineteen percent of young women in developing countries become pregnant before age 18. Around 7.3 million births that occur to adolescent girls under 18 every year in developing countries. It is revealed that West and Central Africa account for 
the largest percentage (6\%) births before the age of 15, while Eastern Europe and Central Asia account for the smallest percentage (0.2\%). One girl in 10 has a child before the age of 15 in Bangladesh, Chad, Guinea, Mali, Mozambique and Niger (UNFPA, 2018).

Age at onset of childbearing is an important demographic indicator. Since early childbearing among adolescent women despite a greater risk to the health of both the mother and child, is very common in South Asia. The finding of Nahar and Jahangir 2013 shows that the timing of first birth depends on various socioeconomic, cultural and demographic factors. Specially, child marriage, gender inequality, poverty, sexual violence and coercion, national policies, restricting access to contraception, age-appropriate sexuality education, lack of access to education and reproductive health services are the major factors for early child birth in developing countries. The proportion of women who became mother before age 20 is a measure of the magnitude of adolescent fertility which is major health and social problem in many countries like Nepal. Though postponement of age at first birth reflecting is increasing the age at marriage or age at union has made a large contribution to decline fertility too.

The report of Nepal Demography and Health Survey 2016 finds out the median age at first birth among the women age 25-49 is 20.4 years which has changed little over the last two decades (19.8 years in 1996 and 20.4 years in 2016). Report also noted that among 17 percent of women at age 15-19 begin childbearing, 13 percent have a live birth and 4 percent are pregnant with their first child. Teenage childbearing has remained constant over the past 5 years. Early childbearing varies by the different background characteristics, where 18 percent of women at age 15-19 in the Terai zone begin childbearing, compared with 17 percent of women in the mountain and 15 percent of those in the hilly region and lowest in Province 3 (10\%) and highest in Province 2 (27\%) (MoHP, 2017).

\section{Objective}

Main objective of this study is to examine the relationship between age at first birth and socio economic and demographic variables (age at marriage, place of residence, educational status, occupation, use of contraception, wealth index) in Nepal.

\section{Methodology}

This article is based on secondary data sources. Research design is descriptive and analytical in nature. Published national and international journal articles, reports are collected to review literature and content analysis. Data from Nepal Demographic Health Survey 2016 (NDHS) are used. Only currently married women (adolescent and youth 
aged 15-24) are used for study purpose and those women who have at least one child are the study women. Therefore, out of total 4,849 women, this study has analyzed only 1,670. Pearson Correlation has been used to test significance level of dependent variable and independent variables. So correlation between age at first birth of women and the explanatory variables (age at marriage, place of residence, educational status, occupation, use of contraception, wealth index and husband education) is measured at the significant level of 0.01 .

\section{Results}

Table 1 presents background characteristics of study women aged 15 to 24 years of age. Majority of study women (54\%) are in 15-19 years of age group while women in $20-24$ age group accounted for the remaining 46 percent. Majority of the study women $(62 \%)$ are from the urban area. Furthermore 76 percent of women completed secondary and above education while 10 percent have no education and only 14 percent completed primary education. Similarly 41 percent of women are from agriculture sector, nearly 16 percent are from non -agriculture sector and nearly 43 percent of women did not work. Janajati occupied 36 percent, Brahmin/Chhetri are 39 percent and Dalit are 13 percent of sampled population. Fifty percent of women are never married and 49 percent are married in that age group. Majority of women (74\%) got married in 15-19 years of age, 11 percent are in less than 15 years of age. The result further indicates that 86 percent of women never used any form of contraceptive methods. Only 10 percent used modern methods and very low 4 percent of women used traditional methods. More than one third (38\%) of women came from household classified as "poor" in the wealth index, while 21 percent and 41 percent are respectively from "middle" and "rich".

Table 1: Background characteristics of women aged 15-24 years

\begin{tabular}{|l|c|c|}
\hline Background Characteristics & Percent & Number \\
\hline Age group of women & \multicolumn{2}{|l|}{} \\
\hline $15-19$ & 53.6 & 2598 \\
\hline $20-24$ & 46.4 & 2251 \\
\hline Place of residence & 61.7 & 2991 \\
\hline Urban & 38.3 & 1858 \\
\hline Rural & 10.0 & 483 \\
\hline Educational status & \\
\hline No education
\end{tabular}




\begin{tabular}{|c|c|c|}
\hline Primary education & 14.3 & 696 \\
\hline Secondary and above & 75.7 & 3671 \\
\hline \multicolumn{3}{|l|}{ Occupational status } \\
\hline Did not work & 42.7 & 2070 \\
\hline Agriculture & 41.4 & 2006 \\
\hline Non Agriculture & 16.0 & 774 \\
\hline \multicolumn{3}{|l|}{ Caste } \\
\hline Brahmin/ Chhetri & 29.3 & 1426 \\
\hline Janajati & 36.2 & 1755 \\
\hline Dalit & 13.2 & 641 \\
\hline Others & 21.3 & 1033 \\
\hline \multicolumn{3}{|l|}{ Marital status } \\
\hline Never married & 50.2 & 2433 \\
\hline Married & 49.3 & 2389 \\
\hline Widowed & 0.1 & 4 \\
\hline Divorced & 0.1 & 6 \\
\hline Separated & 0.4 & 17 \\
\hline \multicolumn{3}{|l|}{ Age at marriage $(n=2501)$} \\
\hline$<15$ & 10.9 & 265 \\
\hline $15-19$ & 73.7 & 1781 \\
\hline $20-24$ & 15.3 & 370 \\
\hline \multicolumn{3}{|l|}{ Use of contraception } \\
\hline No method used & 85.5 & 4144 \\
\hline Only traditional method & 4.1 & 199 \\
\hline Modern method & 10.4 & 506 \\
\hline \multicolumn{3}{|l|}{ Wealth index } \\
\hline Poor & 38.0 & 1841 \\
\hline Middle & 20.9 & 1015 \\
\hline Rich & 41.1 & 1993 \\
\hline Total & 100.0 & 4849 \\
\hline
\end{tabular}

Source: NDHS data set, 2016

Table 2 shows the distribution of age at first birth among adolescent and youth women 
aged 15 to 24 years. Out of total 4,849 cases, 1,670 women had at least one child at the time of survey. It appeared that on average, the age at first birth among these women was reported to 18.40 years. More than fifty percent of women $(65.3 \%)$ have their first birth at 15-19 years of age. Similarly, 28 percent of women have their first birth within 20 to 24 years of age. A small percentage $(6.7 \%)$ of women reported their first birth at less than 15 years of age.

Table 2: The distribution of age of first birth among women aged 15-24 years

\begin{tabular}{|l|c|c|}
\hline Age of first birth & Percent & Number \\
\hline$<15$ & 6.7 & 111 \\
\hline $15-19$ & 65.3 & 1091 \\
\hline $20-24$ & 28.0 & 468 \\
\hline Total & $\mathbf{1 0 0 . 0}$ & $\mathbf{1 6 7 0}$ \\
\hline Missing system & $\mathbf{3 1 7 9}$ \\
\hline Total & $\mathbf{4 8 4 9}$ \\
\hline Mean age at first birth & $\mathbf{1 8 . 4 0}$ \\
\hline
\end{tabular}

Source: NDHS data set, 2016

Table 3 shows the mean distribution and correlation coefficients of age at first birth of women by different socioeconomic characteristics. The variables included in the table are place of residence, educational status, occupation, caste, wealth index, use of contraception and age at marriage. Table indicates that five variable are found to have positive correlation with age at first birth where as other three variables are found to have negative correlation.

Table 3: Mean distribution and correlation coefficients of age at first birth by different socio- economic characteristics of women

\begin{tabular}{|l|l|c|c|c|}
\hline Variables & Categories & Mean & Number & Pearson R \\
\hline \multirow{3}{*}{ Place of residence } & Urban & 18.48 & 884 & \multirow{2}{*}{-.039} \\
\cline { 2 - 4 } & Rural & 18.31 & 786 & \\
\hline \multirow{3}{*}{ Educational status } & No education & 17.62 & 137 & \multirow{2}{*}{$169 * *$} \\
\cline { 2 - 4 } & Primary & 17.74 & 372 & \\
\cline { 2 - 4 } & Secondary and higher & 18.80 & 980 & \\
\hline
\end{tabular}




\begin{tabular}{|c|c|c|c|c|}
\hline \multirow{3}{*}{ Occupational status } & Did not work & 18.42 & 723 & \multirow{3}{*}{.040} \\
\hline & Agriculture & 18.27 & 733 & \\
\hline & Non-agriculture & 18.73 & 213 & \\
\hline \multirow{4}{*}{ Caste } & Brahmin/Chhetri & 19.02 & 412 & \multirow{4}{*}{$-.190 * *$} \\
\hline & Janajati & 18.54 & 556 & \\
\hline & Dalit & 17.93 & 244 & \\
\hline & Others & 17.90 & 458 & \\
\hline \multirow{4}{*}{ Husband education } & No education & 17.60 & 160 & \multirow{4}{*}{$.173 * *$} \\
\hline & Primary education & 17.83 & 351 & \\
\hline & Secondary and higher & 18.70 & 1142 & \\
\hline & Don't know & 16.32 & 2 & \\
\hline \multirow{3}{*}{ Wealth index } & Poor & 18.22 & 705 & \multirow{3}{*}{$.052 *$} \\
\hline & Middle & 18.29 & 420 & \\
\hline & Rich & 18.70 & 544 & \\
\hline \multirow{3}{*}{ Used methods } & No method used & 18.42 & 1082 & \multirow{3}{*}{-.002} \\
\hline & Traditional & 18.49 & 142 & \\
\hline & Modern & 18.31 & 443 & \\
\hline \multirow{3}{*}{ Age at marriage } & $<15$ & 15.75 & 220 & \multirow{3}{*}{$.627 * *$} \\
\hline & $15-19$ & 18.40 & 1283 & \\
\hline & $20-24$ & 21.87 & 167 & \\
\hline
\end{tabular}

Source: NDHS data set, 2016

- Correlation is significant at the 0.01 level (2-tailed). ${ }_{* *}$

- Correlation is significant at the 0.05 level (2-tailed).*

Among positively correlated variables, women with secondary and higher education are more likely to have child at higher (18.80 years) age than compared with no education and primary education. Similarly women with secondary and higher education had higher age at first birth. Husband education is also positively correlated with the age at first birth. Husband with higher education are more likely to have at higher (18.70 years) age 
compared to husband with no education and primary education. Increasing mean age at first birth is found to be correlated with the increasing age at marriage. Women with higher age at marriage are also likely to give birth at higher age. Women with less than 15 years age at marriage, the mean age at first birth was almost 3 years higher compared to 15 to 19 years age at marriage and 6 years higher age at birth for women of 20 to 24 years of age at marriage. Obviously, higher the age at marriage is likely to high age at first birth. Women engaged in non- agriculture sector are likely to have their first birth at slightly higher (18.73 year) age than women who did not work (18.24 year).

Among negatively associated variables, women living in urban area are likely to have first child slightly higher (18.48 years) age than women living in rural area (18.31 year). Similarly, Brahmin/Chhetri women are more likely to have first birth at higher age compared to women of Dalit and other caste. Regarding the use of contraception, the mean age at first birth was slightly higher of traditional method user than women with no method users and women with modern method users. Although above variable show negative co-relation, the difference is very insignificant.

\section{Discussion}

Age of the respondents has a significant effect on the age at first birth. The average age at first birth of women aged 15-24 years observed in the study population was 18.40 years whereas 65.3 percent of women's age at first birth was 15 to 19 years. It was observed that high differences of age at first birth among women aged 15 to 19 and 20 to 24 years. A study in Uganda conducted by Mugarara et. al. (2016) revealed that women aged 21- 29 years have reduced chance of having a first child compared to women who are aged 1520 years which means that the older the woman the lower the chances of having a child. Most of the research revealed that, most probably, the early age at first birth was due to the lower age at marriage (Haque et al., 2008). Age at first marriage has a major effect on age of mothers at first birth because women who marry early have on lower age at first birth (Chowdhury et al., 2017).

It was expected that women in rural area would have a lower age at first birth than urban counterparts (Gurmu \& Etana, 2014). This study found that women with urban area had higher age at first birth than rural area. A study in Uganda conducted by Mugarara et. al. (2016) revealed that women residing in rural areas are 1.73 times more likely to have their first child earlier than those residing in urban areas. The study by Chandrasekhar (2010), indicated that in India women who grew up in the countryside are more likely to have children earlier. 
Education is also one of the factors that determine the age of a woman at first birth. Particularly women's education has a significant effect on fertility. It is believed that no education or low education leads to early child bearing or early motherhood. Women's education was found to have positive impact on age at first birth. It is found that women with no education and primary education have earlier age at first birth than women with Secondary and higher education. A study in Uganda conducted by Mugarara et. al. (2016) indicated that a woman of primary level of education is 0.73 times less likely to have a child at an early age compared to a woman who has no education level and a woman of secondary and higher level of education has reduced chances of having a child at an early age compared to a woman with no level of education.

Occupation is an important factor to determine the level of fertility as well age at first birth. It is expected that women with non-agriculture sector have higher age at first birth then women with agriculture. Regarding on the occupational status, study found that women with non- agriculture have slightly higher (18.72 years) age at first than agriculture (18.27 years). A study in Uganda conducted by Mugarara et. al. (2016) indicated that a woman who is not working is 1.27 times more likely to have the first child at an early age compared to the woman who is working. Similarly, the findings by Rabbi et. al. (2013) which showed that occupation is one of the factors influencing the age at first birth of Bangladeshi women.

Regarding on caste/ethnicity, this study found that Dalit have lower (17.93 years) age at first birth than Brahmin/Chhetri (19.02 years). This variance might be early age at marriage of Dalit women (17 and 16 years for hill and Terai Dalit respectively) than Brahmin/Chhetri and Janajati (CBS, 2014). Lower literacy status is one of the major factor for early marriage. According to population and housing census 2011, the literacy status of Dalit (Hill and Terai) was 62 percent and 35 percent respectively (CBS, 2014).

Regarding on the wealth index, the study found that the positive correlation between age at first birth and wealth index. It shows that the quite higher age at first birth of women from rich household than poor. A study in Swaziland by Mhele (2015) indicated that women who came from household of wealth index classified as rich had the longest duration to first birth with a mean of 18.70 years compared to 18.22 years for those coming from poor household.

This study found that the negative correlation between age at first birth and use of contraceptive method. Women of traditional method users have slightly higher (18.9 years) age then modern contraceptive users. On the other hand, those who never used any method have 18.42 years. The study in Swaziland by Mhele (2015) indicated that women 
with never used method have higher age (19 years) than other.

Age at marriage is one of the vital indicators and influences fertility. Assuming that fertility often takes place within marriage and there is an inverse relationship between age at marriage and fertility. The relationship between marriage and fertility suggests that women who marry at a younger age produce more children than women who marry late (Mugarura et al., 2015). The study further shows that age at marriage has a significant effect on age at first birth. A woman who got married an earlier (Less than 15 years) have had lower (15.75 years) age at first birth than women who got married late age (20 -24 years).

\section{Conclusion}

A woman's first birth is one of the most significant events in her life. This study focused on examining the socio- economic and demographic factors that determine age at first birth among adolescent and youth women aged 15-24 years old. The study found that the average age at first birth is 18.40 years. Education of women, occupational status, wealth index and age at marriage found to have positive association with age at first birth. These variables are the important determinant factors that influence positive roles to increase the age of first birth. Since awareness and education leads toward higher age at first birth, this study therefore recommends to focus on women's awareness through proper education. As study shows adolescent and youth group is sexually very active and vulnerable to unmet need of family planning (34.9\% and 32.6\%), fertility rate is also very high. The use of modern contraceptives in this group is significantly low (10.4\%). Awareness and friendly family planning programme and abundant supply of modern contraceptives toward this group is highly recommended.

\section{References}

Bengali, S. (2015). Great read: Nepal's child grooms suffer in physical, emotional ways. https://www.latimes.com/world/la-fg-c1-nepal-child-grooms-20150127- story.

Bongaarts, J. (2015). Modeling the fertility impact of the proximate determinants: Time for a tune-up. Demographic Research, 33(19). https://www.demographic-research. org/Volumes/Vol33/19/

Central Bureau of Statistic (CBS). (2014). Population monograph of Nepal. Kathmandu: National Planning Commission Secretariat. Central Bureau of Statistic, Government of Nepal, Nepal. 
Chandrasekhar, S. (2010). Factors affecting age at marriage and age at first birth in India. Journal of Quantitative Economics, 8(2), 81-97.

Gurmu, E., \& Etana D. (2014). Age at first marriage and first birth interval in Ethiopia: Analysis of the roles of social and demographic factors. Ethiopia African Population Studies, 28 (3). https://aps.journals.ac.za 1332.

Mhele, K. (2015). Determinants of time to first birth among women 15-24 in Swaziland. African Population Studies, 29(2).

Ministry of Health and Population (MoHP). (2017). Nepal demographic and health survey 2016. Kathmandu: Ministry of Health and Population New ERA and IFC International, Nepal.

Mosammat, Z. N., Mohammad, S. Z., \& Shafiqul, S. M. I. (2013). Age at first marriage and its relation to fertility in Bangladesh. Chinese Journal of Population Resources and Environment, 11(3), 227-235.

Mugarura, A., Kaberuka, W., \& Atuhaire, R. (2016). Factors determining the age at first birth in Uganda. Issues in Scientific Research, 1 (5), 61-66.

Nahar, M. Z., \& Mohommad S. Z. (2013). Pattern and determinant of age at first birth in Bangaladesh. Turkkish Journal of Population Studies, (35), 63-7.

Rabbi, A. M. F., \& Kabir, M. I. (2013). Factors influencing age at first birth of Bangladeshi women- A multivariate approach. American Journal of Public Health Research, 1(7), 191-195.

Regmi, G. P. (1995). A first birth interval in Nepal. Unpublished M.A. dissertation submitted to the Central Department of Population Studies, T.U., and Kathmandu.

United Nations International Children's Emergency Fund (UNICEF). (2018). Ending child marriage in Nepal. https://www.unicef.org/nepal/media/401/file/Ending\%20 Child\%20Marriage\%20in\%20Nepal.pdf.

World Health Organization (WHO). (2019). Maternal mortality. Fact sheet. https://www. who.int/news-room/fact-sheets/detail/maternal-mortality 